\title{
Key Technology Research and Demonstration Application of Green Design and Construction of Zihui Expressway
}

\author{
Jianhao Zheng ${ }^{1}$, Yucai $\mathrm{Wu}^{1}$, Wei Wang ${ }^{1}$, Dan Wang ${ }^{2 *}$ and Xiaodong Shang ${ }^{2}$ \\ ${ }^{1}$ Guangdong Zihui Expressway Co., Ltd, Guangzhou, Guangdong Province, 510030, China \\ ${ }^{2}$ Research Institute of Highway Ministry of Transport, Beijing, 100086, China
}

\begin{abstract}
This paper takes Zihui expressway as an example, from the perspective of green design and construction of mountain expressway, this paper mainly discusses and analyzes the project characteristics and technical requirements of Zihui expressway, and puts forward the key technology of green design and construction based on the establishment of green highway.
\end{abstract}

\section{Introduction}

The rapid economic development has promoted the vigorous development of the transportation. The traditional road construction process consumes a lot of resources and causes serious environmental pollution in the construction process. With the improvement of people's environmental awareness, the green construction concept and construction methods aiming at saving resources and protecting the environment have been widely implemented.

Green design and construction refers to a construction technology that takes low-carbon environmental protection and resource conservation as the construction concept. Based on this, this paper takes the application of green design and construction technology in the construction of Zihui Expressway in Guangdong Province as an example to study the highway construction technology under the background of green highway construction, hoping to attract people's attention to green construction and promote the sustainable, healthy and stable development of highway construction by analysis the importance of the application of green construction in highway construction

\section{Project overview and requests analysis}

\subsection{Project overview}

Zijin of Heyuan county to Huiyang of Huizhou country expressway is the section expressway of Hehui Dongguan Expressway (hereinafter referred to as "Zihui expressway"), which is one of key construction projects of Guangdong Province, and is an important part of the densified connecting line " Longchuan of Heyuan County (boundary between Guangdong and Jiangxi) and
Panyu of Guangzhou " in the expressway network planning of Guangdong Province (2013-2030).

\subsection{Project characters and requests}

The terrain of the project fluctuates greatly, and there are many risk sources and high safety requirements. The geological conditions are poor, so it is difficult to treat. There are many water source protection areas along the line of the project, which have high requirements for environmental security. There are good natural landscape resources and human landscape resources along the project, which requires high requirements for road landscape and service.

Based on this, the project carried out key technology research on green design and construction, and made demonstration applications based on research basis.

\section{Green design}

\subsection{Ecological route selection}

Taking the characteristics of regional topography and landform into full consideration, to minimize the impact on natural reserves, scenic spots and water source reserves, a comparison and selection scheme is carried out for sensitive points (Zhaoyuan reservoir), which is one of a new batch of drinking water source protection areas.

The A3 line is straight, project scale is small, and the impact on S120 is small through research. Although the impact on Zhaoyuan reservoir is slightly large, considering that the impact range is secondary water source, the impact can be minimized by optimizing the line location and doing a good job in environmental protection design. Therefore, in order to reduce the project price and achieve the maximum social and

\footnotetext{
"Corresponding author's e-mail: 38905936@qq.com
} 
economic benefits of the project, the A3 line scheme is adopted in the implementation stage.

The delimitation of forest protection area is of great significance to the protection of ecological environment and the promotion of social sustainable development. In the process of implementation of the project, the data of ecological strict control area along the line are collected and sorted out in detail, and the line position is also avoided to the maximum extent on the basis of ensuring the feasibility, safety and economy of the project.

\subsection{Land conservation and utilization.}

The large temporary project saves land by using the permanent land for the project and renting the land for planning and construction in the local area; the prefabricated beam yard of the whole line is set in the

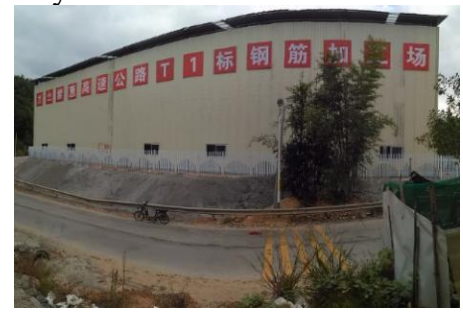

Figure 1. Steel processing plant transferred to local factory

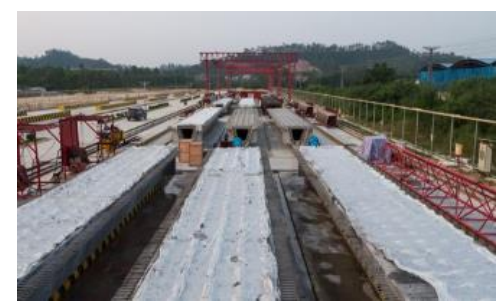

main line; the concrete mixing station, steel processing workshop, small structure prefabrication plant and project management department of most bid sections are set in the maintenance work area, interchange area or use the original office buildings, workshops and open spaces along the line; the construction of construction access road is consistent with the construction planning of rural roads Connect and keep it as rural road in the future.

After the completion of the project, the steel bar shed in section $\mathrm{T} 1$ will be handed over to the local residents for the factory. In section T3, the project department will build the activity board room, site hardening and fitness facilities in the site, and donate them to the local enterprises for free. In section T3, 1 mixing station will rent the mixing equipment of the local enterprises and transfer it to the local enterprises for continuous operation.

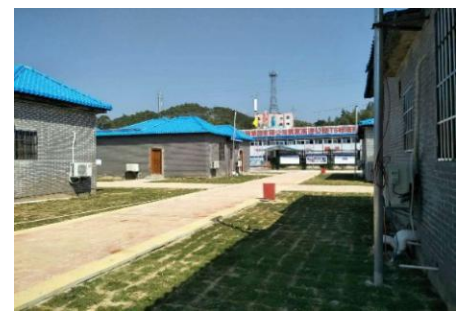

Figure 2. Unfinished building build management

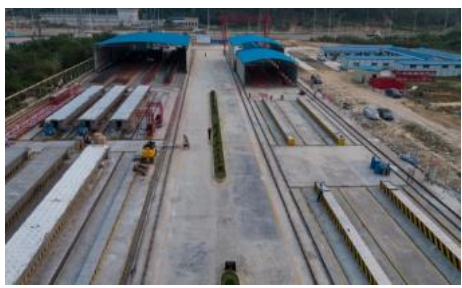

Figure 3. Main line subgrade as precast beam yard
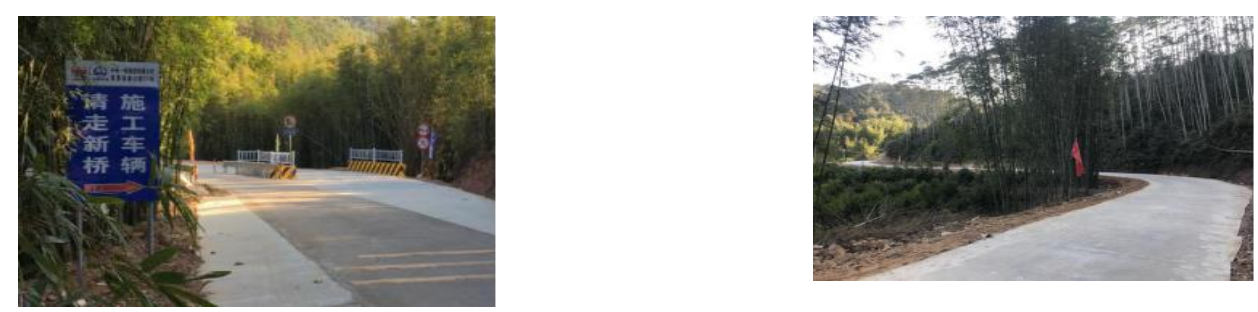

Figure 4.Permanent and temporary combination of construction access road

\subsection{Land improvement and reclamation}

Zihui project occupies about $1237 \mathrm{mu}$ of paddy field, of which $766 \mathrm{Mu}$ is in Heyuan section and $471 \mathrm{Mu}$ is in Huizhou section. According to the new policy of land use approval, organic soil and muddy soil for dredging of main line shall be used for farmland upgrading and transformation, and the soil of original wasteland shall be used for soft foundation replacement of main line, and the land shall be filled and leveled at the roadside to achieve rational utilization of resources. 


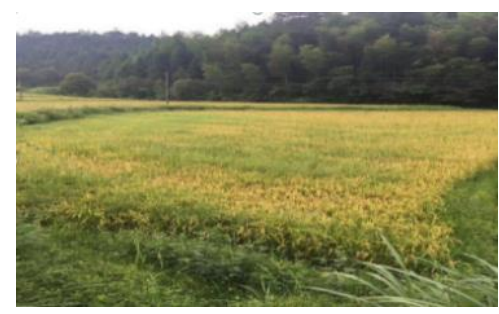

Figure 5. Land improvement and reuse

\section{Green construction}

\subsection{Pollution free excavation of bridge foundation and separation and circulation of slurry and slag}

The new construction technology of bridge pile foundation rotary drilling machine is characterized by flexible construction of luffing mechanism, high working efficiency, compact structure, convenient operation, high degree of automation, saving time of manpower and material resources, low labor intensity, low noise and environmental protection. The vibration can be reduced to overcome the characteristics of drilling and wear requiring mud wall construction and reduce environmental pollution.

In the T4 standard of Zihui expressway, the rotary drilling construction technology and bridge pile foundation slurry and slag separation and circulation mud pool technology have been successfully applied, which are mainly used in the construction of pile foundation of river crossing bridge sensitive to water environment. In the process of hole forming, the mud pool + mud pump is used as the mud circulation structure, so as to realize that the mud does not "land" during the

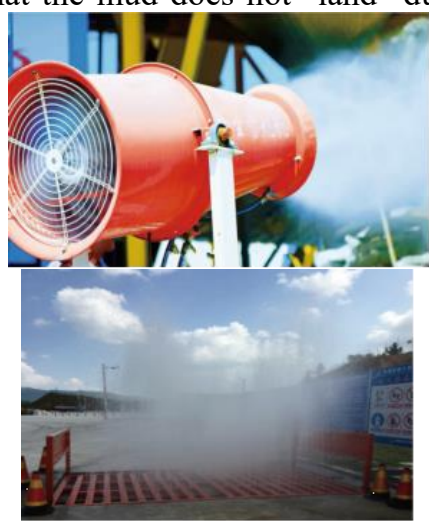

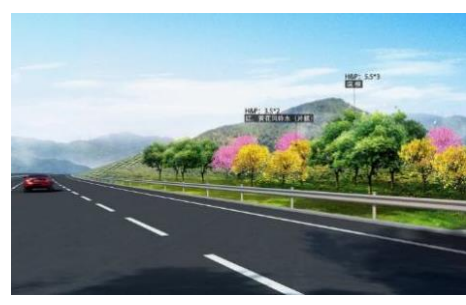

Figure 6.Land making in filling area

process of hole punching and avoid mud pollution to the river

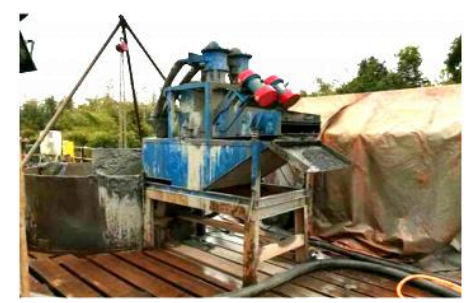

Figure 7. High power silt separator.

\subsection{Construction dust pollution}

Establish the monitoring and monitoring system of construction dust pollution. Basically achieve the "six hundred percent" coverage of enclosure around the construction site, material stacking and covering, wet excavation, road hardening, vehicle cleaning, and closed transportation of muck vehicles in key areas. Reduce the pollution of construction environment, reduce the harm of dust to human body, and ensure the physical and mental health of construction workers

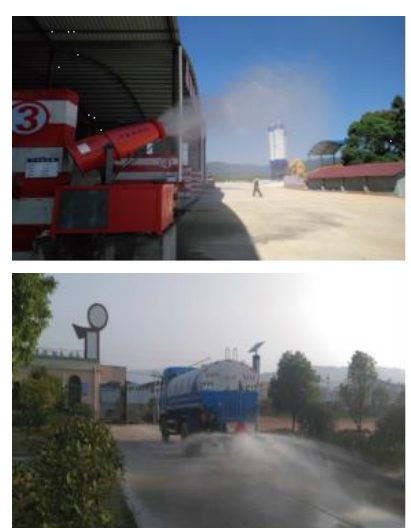

Figure 8.Construction dust pollution control

\subsection{Green mixing station and zero blowdown Technology}

The entrance and exit of the concrete mixing station are equipped with automatic car washing device, wheel washing pool and powder storage tank pulse dust reduction system. The entrance and exit of the mixing station are equipped with automatic car washing device and wheel washing pool: the exit of the mixing station is equipped with automatic car washing device and wheel washing pool. Through the device, dust pollution can be controlled to a certain extent to create a pollution-free working environment.

In order to control dust pollution, a $120 \mathrm{~mm}$ diameter galvanized steel pipe is welded on the top of cement tank of water stabilization station with pulse dust reduction system of powder storage tank. When bulk cement is pumped, the dust enters the dedusting pool through the steel pipe, which is then led into the settling pool through 
the galvanized steel pipe, and finally discharged into the local water system after multistage sedimentation. There are many types and large amounts of crushed stones in asphalt station, which are guaranteed to enter the warehouse through the roller washer Clean the gravel to avoid dust pollution

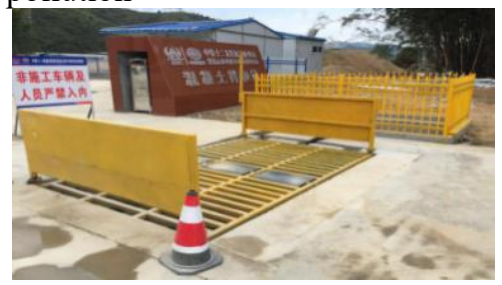

Figure 9. Automatic car washing device and wheel washing pool at the entrance and exit of mixing station.

\subsection{Recycled ecological sound barrier of waste rubber}

Waste rubber recycling type ecological sound barrier waste rubber recycling type ecological sound barrier is designed to solve the two environmental problems of traffic noise pollution and "black pollution" of waste rubber tires. Considering that the waste rubber particles are made of rubber and the strength of single use is not enough, appropriate auxiliary structure shall be selected.

Through screening and proportioning of rubber particles with different particle sizes of waste tires, a rubber particle size composite plate with the best sound absorption and insulation effect is generated, and a suitable auxiliary structural plate (cement, metal, etc.) is selected to form a sound absorption and insulation plate by compounding with the rubber plate. It is applied in the existing sound barrier process to achieve the expansion

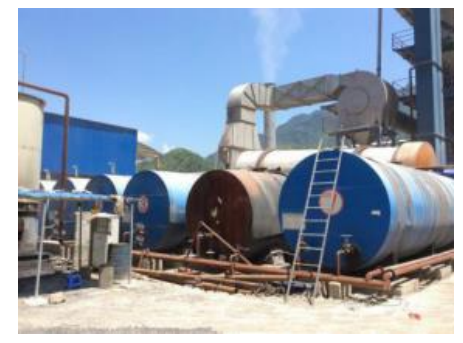

and application effect of low-carbon and low-carbon materials.

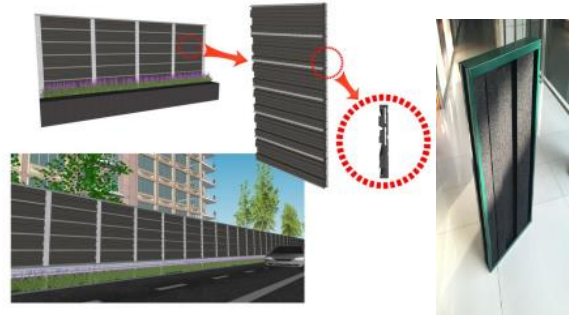

Figure 10. Schematic diagram of rubber regeneration type ecological sound barrier effect.

\subsection{Oil to gas technology of asphalt mixing station}

Traditional asphalt mixing uses fuel oil as fuel. Due to inadequate combustion, pollutants such as asphalt smoke and dust will pollute the atmospheric environment, which is easy to cause hardening of the mixing plant and shorten the service life of the mixing plant. The technology of replacing oil with gas in asphalt mixing plant can improve the combustion quality and reduce environmental pollution. Natural gas (LNG) after lowtemperature liquefaction treatment does not mix with any impurities and has calorific value content It is characterized by high cost, low unit cost and sufficient combustion. It can be used in asphalt mixing plant to replace traditional heavy oil, rubber oil and other fuel oil, which is safe and environmentally friendly. Liquefied natural gas and fuel oil can share a combustion machine. Through different valve switches, the "oil, gas" pipeline can be switched to realize "oil to gas"

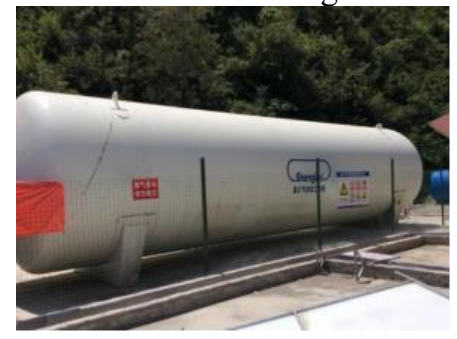

Figure 11. Oil to gas in asphalt mixing station

\subsection{Intelligent spreading and compaction technology of earth shoulder filling}

The earth shoulder paving adopts an innovative modified paving equipment for continuous paving and one-time compaction molding. Under the condition of ensuring the appearance and quality, it can greatly speed up the filling construction progress, reduce a lot of manual investment, improve the working efficiency, reduce the pollution of earth materials to the road surface and surrounding environment, and achieve the purpose of energy conservation and environmental protection

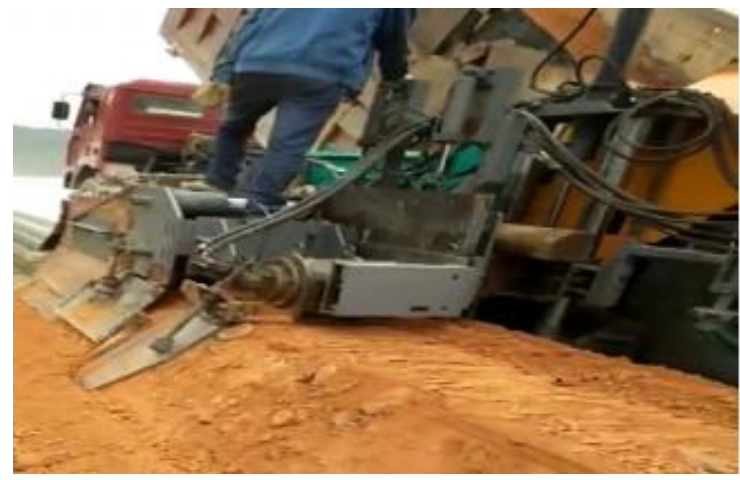

Figure 12. Spreading technology of earth shoulder 


\section{Conclusion}

On the premise of green design, Zihui Expressway carries out green design and route selection to reduce the impact on vulnerable ecological areas like natural reserves and water source reserves. The preliminary design of the project combines technology and roadside filling area to achieve land conservation and rational use of resources. Pollution-free excavation of bridge pile foundation and slurry residue separation recycling technology are adopted to reduce environmental pollution during the project. Dust pollution monitoring and waste rubber recycling ecological sound barrier are carried out on the construction site, which effectively reduces the pollution of solid waste, noise and dust, but also realizes resource conservation and waste recycling, improves the construction level of the highway. It has protected the surrounding ecological environment and demonstrated the green design and construction of green highway construction in Guangdong Province.

\section{Reference}

1. Luke. (2019) On the design concept and application of green highway. Residence,32:116.

2. Wanghaoyu. (2019) Review on the research progress of green construction management mode. value engi neering ,38:48-49.

3. Zhaohui. (2019) Research on construction managem ent of green energy-saving building. Residence, 31:1 55.

4. Shaoziqiang. (2019) Research on the way to realize modern expressway construction management mode guided by green concept. Residence,31:182-183.

5. Yuanweidong. (2018) Research progress of green en ergy-saving building and green construction technol ogy, Construction technology development, 45:117118.

6. Donglihong. (2017) Energy saving and environment al protection concept of Highway Survey and design. Industry and Technology Forum, 16:43-44.

7. Sunzhichao. (2016) Study on energy conservation an d environmental protection of expressway engineeri ng. Traffic energy conservation and environmental $\mathrm{p}$ rotection, 12:53-58.

8. Lidong, Lvping, Lihuayang. (2016) Research progre ss of green construction technology in engineering. Energy save, 35:35-38. 